\title{
The Impact of Body Mass Index and Weight Changes on Disability Transitions and Mortality in Brazilian Older Adults
}

\author{
Flávia Cristina Drumond Andrade, ${ }^{1}$ Ahmad Iqmer Nashriq Mohd Nazan, ${ }^{2}$ \\ Maria Lúcia Lebrão, ${ }^{3}$ and Yeda Aparecida de Oliveira Duarte ${ }^{4}$ \\ ${ }^{1}$ Department of Kinesiology and Community Health, University of Illinois at Urbana-Champaign, 1206 South 4th Street, \\ Champaign, IL 61820, USA \\ ${ }^{2}$ Zilber School of Public Health, University of Wisconsin-Milwaukee, 1240 N. 10th Street, Milwaukee, WI 53205, USA \\ ${ }^{3}$ School of Public Health, Departament of Epidemiology, University of São Paulo, Avenida Dr. Arnaldo, 715 Pinheiros, \\ 01246-904 São Paulo, SP, Brazil \\ ${ }^{4}$ School of Nursing, Department of Medical-Surgical Nursing, University of São Paulo, Avenida Dr. Enéas de Carvalho Aguiar, \\ 419 3o. andar, Sala 318, Cerqueira Cesar, 05403-000 São Paulo, SP, Brazil
}

Correspondence should be addressed to Flávia Cristina Drumond Andrade; fandrade@illinois.edu

Received 2 November 2012; Revised 7 March 2013; Accepted 13 March 2013

Academic Editor: Heather Keller

Copyright (C) 2013 Flávia Cristina Drumond Andrade et al. This is an open access article distributed under the Creative Commons Attribution License, which permits unrestricted use, distribution, and reproduction in any medium, provided the original work is properly cited.

\begin{abstract}
The aim of this study was to examine the association between body mass index and weight changes on disability transitions and mortality among Brazilian older adults. Longitudinal data from the Health, Well-Being, and Aging in Latin America and the Caribbean Study conducted in São Paulo, Brazil (2000 and 2006), were used to examine the impact of obesity on disability and mortality and of weight changes on health transitions related to disability. Logistic and multinomial regression models were used in the analyses. Individuals who were obese were more likely than those of normal weight to have limitations on activities of daily living (ADL), instrumental activity of daily living (IADL), and Nagi's limitations. Obesity was associated with higher incidence of ADL and IADL limitations and with lower recovery from Nagi's limitations. Compared to those who maintained their weight, those who gained weight experienced higher incidence of ADL and Nagi's limitations, even after controlling for initial body mass index. Higher mortality among overweight individuals was only found when the reference category was "remaining free of Nagi limitations." The findings of the study underline the importance of maintaining normal weight for preventing disability at older ages.
\end{abstract}

\section{Introduction}

Brazil is among the 25 countries in the world with the fastest aging rates $[1,2]$. In 1950, 2.6 million (4.9\%) Brazilians were older than 60 years of age, and this number has increased to 20.6 million people (10.8\%) according to the 2010 census [3]. Improvements in medical care and living standards have been shown to translate into higher life expectancy. In 1950, for example, life expectancy at birth in Brazil was 50.9 years, but the figure increased to 72.2 years in 2010 [3]. However, the number of disabled people is expected to increase in the coming years, given the rapid growth rate of the elderly population and the rise in the prevalence of obesity and chronic diseases [4].
Fast changes in the population's nutritional intake that have occurred in Brazil in recent decades [5] have resulted in an increase in the prevalence of obesity $[6,7]$. In the past three decades, obesity rates in Brazil tripled among men and almost doubled among women [6]. With the exception of higherincome urban women [8], the prevalence of obesity is higher among women than among men.

Few studies focus on the impact of BMI on mortality and disability in the Latin American and the Caribbean (LAC) region. Based on the baseline for the Health, Well-Being, and Aging in Latin America and the Caribbean Study (SABE), Al Snih and colleagues [4] showed that obese individuals were 1.6 times more likely to face difficulties performing activities of daily living (ADL) than those with normal BMI [4]. Corona 
and colleagues [9] found that older adults who were underweight $\left(\mathrm{BMI} \leq 23 \mathrm{~kg} / \mathrm{m}^{2}\right)$ and obese $\left(\mathrm{BMI} \geq 30 \mathrm{~kg} / \mathrm{m}^{2}\right)$ were more likely to develop limitations on instrumental activity of daily living (IADL), but their analysis did not explore BMI associations with mortality or recovery from disability. Monteverde and colleagues [10] found that, based on relative cutoffs (quintiles), heavier older adults in Mexico face higher mortality risks than those in the United States. However, when BMI was categorized following the traditional World Health Organization cutoffs, no excess mortality was found among overweight and obese subjects [10]. In fact, coefficients for overweight and obesity were not in the expected direction [10]. However, none of these studies jointly examined the association between BMI, disability transitions, and mortality. This paper addresses this gap in the literature. We examine the association between body mass index and weight changes on disability transitions and mortality.

1.1. Association between BMI and Disability. Obesity has been associated with higher prevalence of disability in cross-sectional and longitudinal studies $[4,11-13]$. This positive association has been found among middle- and older-aged adults [13-15], and it appears that this association has not changed over time $[16,17]$. Additionally, the association between body mass index (BMI) and disability is strongest among those who are underweight $\left(\mathrm{BMI}<18.5 \mathrm{~kg} / \mathrm{m}^{2}\right)$ and among obese subjects $\left(\mathrm{BMI}>30 \mathrm{~kg} / \mathrm{m}^{2}\right)[4,11]$. Obese women face higher prevalence of mobility impairment than men [13]. In the United States, severe functional limitations are higher among older adults who gain or lose weight after age 50 compared to those with stable weight [18]. Emerging evidence supports the proposition that $\mathrm{BMI}$ is an important predictor of the onset of mobility limitations [13]. Older adults in the United States who gain weight over time have higher incidence of mobility limitations than those who maintain their weight [19].

1.2. Association between BMI and Mortality. Large systematic reviews have shown that the relationship between BMI and mortality seems to follow a J-shaped (sometimes U-shaped) curve $[17,20-22]$. All-cause mortality appears to be lowest at BMI levels between 20 and $24.9 \mathrm{~kg} / \mathrm{m}^{2}$ [20,22], with obese individuals facing higher mortality risks than their normalweight counterparts $[20,22,23]$. Recent studies, however, show that overweight individuals have higher life expectancy than individuals of normal weight or those who are obese [12], whereas other studies have an L-shape (see [24], for a short review). Higher mortality at low levels of BMI has been associated primarily with lung cancer and respiratory diseases [22]. At older ages, results from a systematic review and meta-analysis indicated that BMI in the overweight range of $25-29.9 \mathrm{~kg} / \mathrm{m}^{2}$ is not associated with increased mortality [25], whereas other studies have shown that the burden of obesity on mortality seems to be reduced or eliminated among older adults [11, 12, 26-30].

The use of BMI categories has been criticized for not reproducing well the complexities of the BMI and mortality relationship [31-33]. These authors have suggested that the use of alternative models to assess this association. Gronniger
[33] used semiparametric models and found that men in the mild-obese category (BMIs of $30-35 \mathrm{~kg} / \mathrm{m}^{2}$ ) had similar mortality than those of normal weight, but among women BMI levels above $27 \mathrm{~kg} / \mathrm{m}^{2}$ were associated with higher mortality in the U.S. Wong and colleagues [31] used multivariable fractional polynomials to explore the association between BMI and mortality in a sample of adults in the UA They found that the best fitting model contained the powers -1 and -2 for BMI [31]. Their results indicated that the nadir of the BMI mortality curve was in the normal range for women but overweight range for men [31]. Zajacova and Burgard [32] used generalized additive models and found that the nadir was at BMIs 23 to 26, which is also in the normal overweight range. However, they point out that there are important differences depending on the cause of death. For example, the association between BMI and diabetes mortality increases monotonically, but, for all-cause mortality, it followed more a V-shape [32]. However, even though these alternative models often provide better fit to the data, the results of these studies are often interpreted making references for traditional cutoffs as they are more easily understood by the general audience and health practitioners. The use of BMI and BMI categories have also been criticized because it can be related to underlying health status [17]. For example, individuals may be underweight based on their BMI because they have health conditions such as cancer, thyroid problems, infectious, or digestive diseases that lead to low body weight. One approach to address this limitation has been to take into account body weight changes [17].

Our study uses data a large cohort study conducted in São Paulo, Brazil, to examine the association between BMI and body weight changes on disability transitions and mortality, while controlling for a series of demographic, socioeconomic, and health determinants. We investigate these associations on three types of disability (activities of daily living, instrumental activities of daily living, and Nagi's limitations) transitions.

\section{Materials and Methods}

Data from the two waves (2000 and 2006) of the SABE cohort study conducted in São Paulo, Brazil, were used in this study. SABE is a multicenter survey with respondents in seven major cities throughout LAC countries that have been investigating the health and well-being of older adults (age 60 and over). The study was approved by the Institutional Review Boards at the collaborating institutions [34,35], and the participants provided consent to have their data used for research purposes.

The baseline sample was obtained using a two-stage stratified sampling based on the 1995 National Household Survey master sampling frame. The data in the first wave were collected in two stages. The first stage was a household interview conducted by a single interviewer using a standardized questionnaire that included several questions about the living conditions and health status of the subjects. The second stage of data collection consisted of a household visit by a pair of interviewers who completed anthropometric and physicalperformance measurements. At baseline, the response rates 
reached $84.6 \%$ in São Paulo. In the first stage, information on 2,143 individuals was collected. Additional characteristics of the baseline data collection process have been described elsewhere [36-38].

In 2006, to reestablish contact, trained interviewers visited the addresses and neighborhoods of surviving participants from the 2000 survey. For those not found during these visits, interviewers used the additional contact information collected at baseline (e.g., telephone numbers of children or other relatives) to obtain further information about the subjects' current location. In 2006, researchers collected data via face-to-face interviews using a standardized questionnaire. The 2006 questionnaire was very similar to the one used in 2000 but included additional questions that complemented the previous study. Vital statistics records were used to identify subjects who had died between 2000 and 2006. The search was based on the names, sex, dates of birth, and addresses listed in the 2000 database.

Of the 2,143 participants in the first wave of SABE São Paulo, 355 (16.6\%) had missing data on selected variables. Most of them $(n=347)$ had missing data on BMI measure. Those with missing data were older (75.1 years) than those with complete data ( 72.9 years) $(P=0.0001)$, but there were no sex differences. The prevalence of all measures of disability was higher among those with missing data $(P<0.001)$. The final sample is composed of 1,788 individuals, with a subset of 961 with weight change included in the analyses. There were 473 participants who died between the baseline and the followup in 2006.

2.1. Measures. Self-reported disability in six ADL measures (dressing, bathing, eating, getting in and out of a bed, toileting, and getting across a room) were used to measure disability. Individuals were given the following introduction: "Here are a few everyday activities. Please tell me if you have any difficulty with these because of a health problem. Exclude any difficulties you expect to last less than three months." After this introduction, they were asked "Do you have difficulty...?" And the possible answers were: "yes," "no," "does not know," and "no response" for each one of the six ADL measures. Participants who answered "does not know" and "no response" were classified as missing. IADL questions followed the ADL ones. No additional introduction was made. Individuals were asked "Do you have difficulty. . .?" The IADL items included were preparing a hot meal, managing money, shopping, using of transportation within the community, ability to use the telephone, and responsibility for one's own medications. The possible answers were "yes," "no," "cannot do it," "does not know," and "no response." Those who answered "cannot do it" were classified as having difficulty performing the activity, whereas those answering "does not know" and "no response" were classified as missing. The Nagi physical performance measure included lifting or carrying objects that weighed five kilograms or more; lifting a coin; pulling or pushing a large object, such as a living-room chair; stooping, kneeling, or crouching; and reaching or extending the arms above shoulder level. Each of the three disability measures was converted into binary form, in which respondents scored "0" if they did not indicate any limitations and " 1 " if they reported having difficulty performing one or more activity in the scale.

Body weight and height were measured without shoes and with light clothing by trained examiners. BMI was calculated as $\mathrm{kg} / \mathrm{m}^{2}$. Four BMI categories were defined according to the criteria adopted by the Pan American Health Organization for the SABE study [38]: underweight $(\mathrm{BMI} \leq 23.0)$, normal (BMI $>23$ and $<28)$, overweight $(\mathrm{BMI} \geq 28.0$ and $<30$ ), and obese (BMI $\geq 30)$. Change in BMI was calculated as BMI in 2006 minus the BMI at baseline. This difference was divided by the baseline BMI and then recoded into three categories: (a) an increase of $5 \%$ or more; (b) a decrease of $5 \%$ or more; and (c) changes within $5 \%$ of the baseline weight (reference category) $[19,39]$.

The following sociodemographic characteristics were included in the analysis: age (in years), gender, smoking status (never, former, or current smoker), schooling (in years of formal education), and household arrangement (living alone or accompanied). All regression analysis also included a measure of number of chronic conditions at the baseline. Health status based on the number of self-reported chronic conditions included diabetes, hypertension, cardiovascular disease, stroke, cancer, arthritis, and osteoporosis.

STATA S.E. 12.1 for Windows (StataCorp, College Station, TX) was used for all the statistical analyses. Descriptive statistics were conducted first. Weighted logistic regressions were then used to assess the influence of BMI on disability prevalence. Multinomial logistic regressions were used to assess the influence of BMI on disability transitions and mortality. For those free of disability, four outcomes were considered in the multinomial logistic regressions: remained free of disability (reference category), became disabled (incidence), died, or were lost to followup. For those who were disabled at the baseline, four outcomes were included in the multinomial logistic regressions: remained disabled (reference category), recovered from disability, died, or were lost to followup. Multinomial logistic regressions were used to analyze the role of weight change on health transitions as discussed above, excluding mortality, as we do not have information on weight change prior to death in between waves.

In the baseline, there were 1,420 individuals free of ADL and 368 individuals with ADL. In 2006, among those free of ADL, 606 individuals had remained free of ADL, 226 had developed ADL, 329 had died, and 259 were lost in the followup or had missing data on ADL status. Among those who had ADL in the baseline, 99 remained with ADL, 75 recovered from ADL, 144 died and 50 were lost in the followup or had missing data on ADL in 2006. For IADL limitations, 1,207 were free of IADL, and 581 had IADL in the baseline. Among those who were free of IADL in the baseline, 491 remained free of limitations, 257 developed IADL, 230 had died, and 229 were lost in the followup or had missing data on IADL in the second wave. Among those with IADL in the baseline, 220 remained with IADL, 36 recovered from IADL, 243 had died, and 82 were lost in the followup or had missing data on IADL status in 2006. Regarding the Nagi, 654 participants were free of it in 2000, and 1,134 had at least one Nagi limitation. Among those free of Nagi, 192 remained free of it, 210 
developed Nagi, 129 died, and 123 were lost in the followup or had missing data on the Nagi variable in 2006. Among those who had at least one Nagi limitation in 2000, 539 remained with Nagi's limitations, 70 recovered from Nagi's limitations, 344 died, and 181 were lost in the followup or had missing data on Nagi's limitations in the second wave.

\section{Results}

In the final sample, $23.4 \%$ were underweight, $43.3 \%$ had normal weight, $12.4 \%$ were overweight, and $21.1 \%$ of the participants were classified as obese. Table 1 presents the prevalence estimates of disability according to measures of ADL, IADL, and Nagi's limitations by sex and BMI category at baseline. Prevalence of ADL and Nagi's limitations was highest among obese individuals, whereas prevalence of IADL was highest among underweight older adults. Weighted estimates indicated that $16.7 \%$ of the sample in São Paulo had difficulty performing at least one ADL. Prevalence of IADL reached 24.4\%, and most (57.8\%) of the older Brazilian adults reported Nagi's limitations. In logistic regressions, after adjusting for age and sex (not shown), individuals who were underweight did not differ from those of normal weight on their likelihood of reporting having ADL, IADL, or Nagi in the baseline. Obese individuals were more likely than normal weight participants to report having at least one $\mathrm{ADL}(\mathrm{OR}=1.8,95 \% \mathrm{CI}=1.2$, 2.6) and Nagi's limitations ( $\mathrm{OR}=2.5,95 \% \mathrm{CI}=1.8,3.6)$. There were no statistical differences between normal weight and obese participants regarding IADL prevalence at baseline. There were no statistical differences between normal and overweight subjects regarding ADL and IADL prevalence at baseline, but overweight individuals were more likely than those of normal weight to have Nagi's limitations $(\mathrm{OR}=1.6$, $95 \% \mathrm{CI}=1.1,2.2$ ). Women were more likely than men to report having ADL, IADL, and Nagi's limitations at baseline $(P<0.05)$.

Table 2 shows the multinomial logistic regression results of the disability transitions and mortality between 2000 and 2006 among those who were free of disability in the baseline. Compared to normal weight individuals, obese individuals were more likely to develop ADL $(\mathrm{RRR}=2.1)$ and IADL $(R R R=2.4)$, whereas individuals who were underweight were more likely to develop IADL $(\mathrm{RRR}=1.9)$. Mortality risks were higher among those who were overweight $(\mathrm{RRR}=2.5) \mathrm{com}$ pared to those of normal weight in the Nagi model in which the reference category was remaining free of Nagi's limitations. For all measures of disability, the risk of becoming disabled increased with age. As expected, older age was associated with higher mortality. Women were more likely to develop ADL and Nagi's limitations, but not IADL, between waves. Women had lower mortality in the ADL and IADL models. Higher number of chronic conditions was associated with higher mortality and higher incidence of ADL and IADL.

Table 3 shows the multinomial logistic regression results of the disability transitions and mortality between 2000 and 2006 among those who had disability in the baseline. Being obese was also associated with lower recovery from Nagi
$(\mathrm{RRR}=0.46)$ versus remaining with at least one Nagi limitation. Older age and higher number of chronic conditions were negatively associated with recovery.

In the last set of analyses, we focus on the role of weight gain between waves on disability transitions (Table 4 ). The analyses are restricted to those who have survived between waves. The results presented in Table 4 indicate that those who gained weight between waves were more likely to develop ADL $(\mathrm{RRR}=2.3)$ and Nagi's limitations $(\mathrm{RRR}=2.2)$ than those who maintained their weight, even after controlling for initial BMI categories and other covariates. Higher age was also associated with higher incidence of disability. Women faced higher incidence of ADL $(\mathrm{RRR}=1.8)$ and Nagi $(R R R=2.4)$ than men. Obesity was associated with higher incidence of ADL and IADL. Underweight individuals were more likely to develop IADL. Individuals with more chronic conditions also faced higher incidence of ADL and IADL limitations. When the analyses focused on those who had disability in the baseline, we found that weight gain was associated with lower recovery from $\mathrm{ADL}(\mathrm{RRR}=0.18)$. Older age was negatively associated with recovery from disability. A higher number of chronic conditions were associated with lower recovery of ADL and Nagi. Obesity was negatively associated with recovery from Nagi's limitations.

\section{Discussion}

Most previous studies have focused on the association between BMI and disability $[4,9,13,15,16]$ or BMI and mortality $[10,20-29,31-33]$, but few have analyzed the effect of BMI on both disability and mortality $[11,12,14,30]$. Using three disability measures and data from a large cohort study, this study contributes to the literature by exploring the impact of BMI and weight changes on disability status transitions and on mortality. This study confirmed the negative effects of obesity on disability in São Paulo, Brazil. Higher levels of Nagi's limitations were also found among those who were overweight at baseline. Most longitudinal studies have found that obese older adults are more likely to have experienced incidence of disability in the followup than those of normal weight $[13,14,40]$, and our study confirmed these findings. Older adult Brazilians who were obese at baseline faced higher risks of becoming disabled with ADL or IADL limitations compared to those of normal weight. However, being overweight was not associated with higher incidence of disability after controls were included in the analysis, which is consistent with previous findings [41]. In terms of recovery, we also found that obese individuals were less likely to recover (versus remaining disabled in the followup), as other studies have also found [40].

There is growing interest in the role of weight changes on health transitions $[13,18,19,42]$. Studies have shown that weight gain in older adults is associated with decreased physical function and role limitations $[18,19]$. We found similar findings in which older adults who gained weight between waves were more likely to develop ADL and Nagi's limitations than those who maintained their weight, even after controlling for initial BMI categories. Al Snih and colleagues [19] 
TABle 1: Prevalence of ADL, IADL, and Nagi’s limitations, by sex and BMI categories, São Paulo, 2000 (weighted estimates).

\begin{tabular}{|c|c|c|c|c|c|c|}
\hline & Total & Underweight & Normal & Overweight & Obese & $P$ \\
\hline Total & $n=1,788$ & $n=419$ & $n=775$ & $n=217$ & $n=377$ & \\
\hline $\mathrm{ADL}$ & 16.7 & 14.7 & 13.9 & 18.2 & 23.4 & $* *$ \\
\hline IADL & 24.4 & 28.9 & 21.0 & 25.0 & 26.7 & $* *$ \\
\hline Nagi & 57.8 & 52.7 & 50.7 & 61.5 & 74.9 & $* * *$ \\
\hline Females & $n=1,062$ & $n=212$ & $n=415$ & $n=130$ & $n=305$ & \\
\hline $\mathrm{ADL}$ & 19.8 & 14.8 & 17.2 & 22.2 & 25.4 & $* *$ \\
\hline IADL & 30.5 & 36.5 & 26.7 & 33.8 & 30.4 & \\
\hline Nagi & 67.2 & 59.7 & 60.5 & 73.9 & 78.3 & $* * *$ \\
\hline Males & $n=726$ & $n=207$ & $n=360$ & $n=87$ & $n=72$ & \\
\hline $\mathrm{ADL}$ & 12.3 & 14.5 & 10.3 & 13.4 & 15.7 & \\
\hline IADL & 15.6 & 19.9 & 14.6 & 13.9 & 12.7 & \\
\hline Nagi & 44.1 & 44.4 & 39.6 & 45.9 & 61.8 & $* *$ \\
\hline
\end{tabular}

ADL: activities of daily living; IADL: instrumental activities of daily living.

${ }^{* * *} P<0.001 ;{ }^{* *} P<0.05 ;{ }^{*} P<0.10$.

also reported higher ADL incidence among individuals who had weight gain of more than $5 \%$ between waves. Studies have reported contradictory findings related to weight loss. Some studies have indicated that weight loss is associated with improvements in mobility and functioning [13], whereas others have reported increased ADL disability [19]. Weightloss therapy among obese older adults seems to be beneficial for improving quality of life and physical functioning [43]. Ritchie and colleagues [42] found that intentional weight loss was not associated with functional decline; however, those who unintentionally lost weight faced higher rates of functional decline, regardless of the initial BMI. In our study, we found no differences between those who lost weight and those who maintained weight on disability transitions after controlling for initial BMI. Given the lack of data on intent related to weight changes, further studies are necessary to explore the impact of weight change on mortality and disability in Latin American countries.

In additional analyses (not shown and available upon request), we have explored additional models to test whether BMI and weight changes influence changes in the number of disabilities over time. We found that obesity was associated with the increases in the number of Nagi's limitations. Weight loss and weight gain were associated with an increase in the number of ADL and Nagi's limitations over time. Changes in the number of IADL limitations were not statistically associated with BMI categories or weight changes. As expected, older age was associated with the increases in the number of ADL, IADL, and Nagi's limitations over time. A higher number of chronic conditions were also associated with an increase in the number of ADL, IADL and Nagi's limitations over time. Being female was also positively associated with increases in the number of Nagi limitations. We also tested fractional polynomial models following the approach suggested by Wong and colleagues [31] to examine the relationship between BMI, disability and mortality (results available upon request), and our main conclusions remain the same, which indicates that findings are robust to different model specifications.
The only mortality differential by BMI categories was found among overweight participants who were more likely to die than to remain free of Nagi's limitations. In further analyses (not shown), results from a logistic regression that controlled for the same covariates included in this study, revealed no differences in mortality among underweight, normal weight, overweight, and obese participants. This is consistent with previous studies suggesting that the association between BMI and mortality becomes less U-shaped at older ages [44], and others that suggest that higher BMI may not be detrimental for mortality at older ages [12]. Monteverde and colleagues [10] also did not find statistical differences in mortality among older adults between higher BMI categories (overweight and obese) and normal subjects when using traditional BMI cutoffs, though they reported statistical differences when BMI was categorized in relative terms. However, some studies allude to the fact that the association between BMI and mortality is differential between individuals who are healthy versus those with chronic conditions [45]. The obesity paradox literature indicates that excess weight is actually protective among patients with chronic disease [45]. In our sample, there were no mortality differentials by BMI categories among those with chronic conditions, but overweight individuals free of chronic conditions had lower mortality than those of normal weight (results available upon request).

Our findings also contribute to a growing debate in the field about whether greater life expectancy implies better health for the expanding surviving elderly female population in Latin America [37, 46-51]. We found that Brazilian women experience higher levels of disability than men, which is consistent with previous studies [52, 53]. Previous studies have indicated that Brazilian women face lower mortality than their male counterparts $[37,54]$, and this study confirms these findings.

Aging is related to the increase of fat mass, and there is growing evidence of the detrimental impact of obesity on disability at older ages. There is evidence as well that changes in lifestyle, such as walking, have positive effects on preventing 
TABLE 2: Relative risk ratios of the impact of body mass index categories on disability transitions and mortality among those who were free of disability in the baseline, São Paulo, Brazil-2000-2006.

\begin{tabular}{|c|c|c|c|c|c|c|c|c|c|}
\hline \multirow{2}{*}{ Variables } & \multicolumn{2}{|r|}{$\mathrm{ADL}$} & \multirow{2}{*}{$P$} & \multicolumn{2}{|r|}{ IADL } & \multirow{2}{*}{$P$} & \multicolumn{2}{|r|}{ NAGI } & \multirow{2}{*}{$P$} \\
\hline & $\mathrm{RRR}^{\mathrm{a}}$ & $95 \%$ CI & & RRR & $95 \%$ CI & & RRR & $95 \% \mathrm{CI}$ & \\
\hline \multicolumn{10}{|l|}{ Incidence of disability } \\
\hline Age & 1.10 & {$[1.07,1.13]$} & $* * *$ & 1.11 & {$[1.08,1.14]$} & $* * *$ & 1.05 & {$[1.01,1.09]$} & $* *$ \\
\hline Female & 1.70 & {$[1.06,2.73]$} & $*$ & 1.48 & {$[0.86,2.54]$} & & 2.37 & {$[1.40,4.02]$} & $* *$ \\
\hline \multicolumn{10}{|l|}{ Smoking status } \\
\hline Former smoker & 0.94 & {$[0.60,1.46]$} & & 1.15 & {$[0.68,1.94]$} & & 1.36 & {$[0.80,2.32]$} & \\
\hline Current smoker & 1.58 & {$[0.88,2.85]$} & & 1.52 & {$[0.73,3.16]$} & & 0.93 & {$[0.52,1.65]$} & \\
\hline Number of chronic conditions & 1.56 & {$[1.33,1.83]$} & $* * *$ & 1.33 & {$[1.12,1.58]$} & $* *$ & 1.23 & {$[0.94,1.62]$} & \\
\hline Schooling & 0.95 & {$[0.86,1.04]$} & & 0.91 & {$[0.82,1.00]$} & & 0.88 & {$[0.79,0.98]$} & * \\
\hline Live alone & 0.81 & {$[0.50,1.31]$} & & 0.61 & {$[0.35,1.06]$} & & 0.93 & {$[0.39,2.24]$} & \\
\hline \multicolumn{10}{|l|}{ BMI categories } \\
\hline Underweight & 1.16 & {$[0.66,2.01]$} & & 1.92 & {$[1.21,3.03]$} & $* *$ & 1.03 & {$[0.56,1.89]$} & \\
\hline Overweight & 0.93 & {$[0.49,1.75]$} & & 1.57 & {$[0.84,2.96]$} & & 1.86 & {$[0.89,3.87]$} & \\
\hline Obese & 2.07 & {$[1.21,3.57]$} & $* *$ & 2.42 & {$[1.65,3.53]$} & $* * *$ & 1.19 & {$[0.63,2.26]$} & \\
\hline \multicolumn{10}{|l|}{ Mortality } \\
\hline Age & 1.11 & {$[1.08,1.14]$} & $* * *$ & 1.13 & {$[1.10,1.16]$} & $* * *$ & 1.11 & {$[1.07,1.16]$} & $* * *$ \\
\hline Female & 0.60 & {$[0.38,0.95]$} & $*$ & 0.41 & {$[0.25,0.65]$} & $* * *$ & 0.68 & {$[0.34,1.36]$} & \\
\hline \multicolumn{10}{|l|}{ Smoking status } \\
\hline Former smoker & 1.25 & {$[0.82,1.90]$} & & 1.17 & {$[0.67,2.03]$} & & 0.90 & {$[0.46,1.77]$} & \\
\hline Current smoker & 2.89 & {$[1.66,5.03]$} & $* * *$ & 2.69 & {$[1.36,5.33]$} & $* *$ & 2.68 & {$[1.13,6.37]$} & $*$ \\
\hline Number of chronic conditions & 1.40 & {$[1.16,1.68]$} & $* * *$ & 1.41 & {$[1.17,1.69]$} & $* * *$ & 1.82 & {$[1.25,2.64]$} & $* *$ \\
\hline Schooling & 0.95 & {$[0.89,1.02]$} & & 0.94 & {$[0.87,1.02]$} & & 0.93 & {$[0.82,1.07]$} & \\
\hline Live alone & 1.01 & {$[0.62,1.63]$} & & 1.16 & {$[0.64,2.12]$} & & 1.36 & {$[0.66,2.79]$} & \\
\hline \multicolumn{10}{|l|}{ BMI categories } \\
\hline Underweight & 1.21 & {$[0.79,1.85]$} & & 1.22 & {$[0.71,2.09]$} & & 1.87 & {$[0.95,3.66]$} & \\
\hline Overweight & 1.30 & {$[0.78,2.14]$} & & 1.41 & {$[0.80,2.48]$} & & 2.50 & {$[1.01,6.15]$} & * \\
\hline Obese & 1.07 & {$[0.65,1.75]$} & & 1.29 & {$[0.77,2.18]$} & & 0.68 & {$[0.22,2.07]$} & \\
\hline \multicolumn{10}{|c|}{ Lost to followup or missing disability status in 2006} \\
\hline Age & 1.03 & {$[1.00,1.05]$} & * & 1.05 & {$[1.02,1.08]$} & $* * *$ & 1.03 & {$[0.99,1.08]$} & \\
\hline Female & 1.38 & {$[0.99,1.94]$} & & 1.24 & {$[0.84,1.83]$} & & 2.19 & {$[1.37,3.52]$} & $* *$ \\
\hline \multicolumn{10}{|l|}{ Smoking status } \\
\hline Former smoker & 1.36 & {$[0.90,2.06]$} & & 1.54 & {$[1.00,2.38]$} & & 2.01 & {$[1.10,3.70]$} & * \\
\hline Current smoker & 1.05 & {$[0.60,1.84]$} & & 1.02 & {$[0.53,1.98]$} & & 1.32 & {$[0.61,2.89]$} & \\
\hline Number of chronic conditions & 1.12 & {$[0.96,1.31]$} & & 1.12 & {$[0.94,1.34]$} & & 1.22 & {$[0.94,1.58]$} & \\
\hline Schooling & 1.02 & {$[0.92,1.13]$} & & 1.01 & {$[0.91,1.12]$} & & 0.99 & {$[0.85,1.16]$} & \\
\hline Live alone & 1.37 & {$[0.84,2.22]$} & & 1.42 & {$[0.84,2.40]$} & & 0.93 & {$[0.38,2.30]$} & \\
\hline \multicolumn{10}{|l|}{ BMI categories } \\
\hline Underweight & 1.58 & {$[0.97,2.59]$} & & 2.07 & {$[1.24,3.45]$} & $* *$ & 1.44 & {$[0.70,2.98]$} & \\
\hline Overweight & 1.25 & {$[0.69,2.26]$} & & 1.33 & {$[0.78,2.26]$} & & 1.41 & {$[0.59,3.35]$} & \\
\hline Obese & 1.36 & {$[0.87,2.12]$} & & 1.55 & {$[1.02,2.37]$} & $*$ & 1.32 & {$[0.56,3.14]$} & \\
\hline$N$ & & 1,420 & & & 1,207 & & & 654 & \\
\hline $\mathrm{BIC}^{\prime}$ & & -104.55 & & & -82.451 & & & 47.73 & \\
\hline
\end{tabular}

ADL: activities of daily living; IADL: instrumental activities of daily living; RRR: relative risk ratio; CI: confidence interval; BMI: body mass index.

${ }^{a}$ Remaining free of disability is the reference category. Normal weight is the reference category for BMI, living accompanied is the baseline category for household arrangement, and never smoked is the reference category for smoking status.

${ }^{* * *} P<0.001 ;{ }^{* *} P<0.05 ;{ }^{*} P<0.10$. 
TABLE 3: Relative risk ratios of the impact of body mass index categories on disability transitions and mortality among those who had disability in the baseline, São Paulo, Brazil-2000-2006.

\begin{tabular}{|c|c|c|c|c|c|c|c|c|c|}
\hline \multirow{2}{*}{ Variables } & \multicolumn{2}{|r|}{$\mathrm{ADL}$} & \multirow{2}{*}{$P$} & \multicolumn{2}{|r|}{ IADL } & \multirow{2}{*}{$P$} & \multicolumn{2}{|r|}{ NAGI } & \multirow{2}{*}{$P$} \\
\hline & $\mathrm{RRR}^{\mathrm{a}}$ & $95 \% \mathrm{CI}$ & & RRR & $95 \% \mathrm{CI}$ & & RRR & $95 \% \mathrm{CI}$ & \\
\hline \multicolumn{10}{|l|}{ Recovery from disability } \\
\hline Age & 0.93 & {$[0.88,0.97]$} & $* *$ & 0.92 & {$[0.87,0.98]$} & $* *$ & 0.96 & {$[0.92,1.00]$} & * \\
\hline Female & 0.65 & {$[0.25,1.73]$} & & 0.39 & {$[0.13,1.17]$} & & 0.56 & {$[0.30,1.07]$} & \\
\hline \multicolumn{10}{|l|}{ Smoking status } \\
\hline Former smoker & 0.39 & {$[0.11,1.33]$} & & 1.04 & {$[0.42,2.57]$} & & 1.54 & {$[0.72,3.27]$} & \\
\hline Current smoker & 1.43 & {$[0.49,4.18]$} & & 0.55 & {$[0.11,2.79]$} & & 1.01 & {$[0.41,2.49]$} & \\
\hline Number of chronic conditions & 0.72 & {$[0.52,0.99]$} & $*$ & 0.93 & {$[0.68,1.27]$} & & 0.59 & {$[0.44,0.79]$} & $* * *$ \\
\hline Schooling & 1.03 & {$[0.83,1.27]$} & & 0.99 & {$[0.76,1.28]$} & & 1.05 & {$[0.89,1.25]$} & \\
\hline Live alone & 0.55 & {$[0.17,1.74]$} & & 1.11 & {$[0.31,3.92]$} & & 3.24 & {$[1.59,6.57]$} & $* *$ \\
\hline \multicolumn{10}{|l|}{ BMI categories } \\
\hline Underweight & 0.37 & {$[0.10,1.34]$} & & 0.14 & {$[0.01,1.45]$} & & 0.62 & {$[0.25,1.58]$} & \\
\hline Overweight & 1.01 & {$[0.35,2.97]$} & & 0.80 & {$[0.22,2.88]$} & & 0.82 & {$[0.29,2.28]$} & \\
\hline Obese & 0.48 & {$[0.21,1.08]$} & & 0.77 & {$[0.28,2.17]$} & & 0.46 & {$[0.22,0.97]$} & * \\
\hline \multicolumn{10}{|l|}{ Mortality } \\
\hline Age & 1.12 & {$[1.07,1.18]$} & $* * *$ & 1.07 & {$[1.04,1.10]$} & $* * *$ & 1.10 & {$[1.08,1.12]$} & $* * *$ \\
\hline Female & 0.40 & {$[0.18,0.90]$} & $*$ & 0.65 & {$[0.30,1.38]$} & & 0.48 & {$[0.30,0.77]$} & $* *$ \\
\hline \multicolumn{10}{|l|}{ Smoking status } \\
\hline Former smoker & 1.33 & {$[0.57,3.09]$} & & 1.75 & {$[0.92,3.34]$} & & 1.75 & {$[1.13,2.69]$} & * \\
\hline Current smoker & 3.35 & {$[1.06,10.64]$} & $*$ & 3.09 & {$[1.35,7.07]$} & $* *$ & 2.30 & {$[1.29,4.09]$} & $* *$ \\
\hline Number of chronic conditions & 0.87 & {$[0.67,1.14]$} & & 0.97 & {$[0.79,1.19]$} & & 0.98 & {$[0.86,1.13]$} & \\
\hline Schooling & 0.98 & {$[0.82,1.17]$} & & 1.04 & {$[0.93,1.16]$} & & 0.95 & {$[0.89,1.02]$} & \\
\hline Live alone & 1.03 & {$[0.42,2.50]$} & & 0.88 & {$[0.53,1.45]$} & & 1.23 & {$[0.77,1.97]$} & \\
\hline \multicolumn{10}{|l|}{ BMI categories } \\
\hline Underweight & 0.97 & {$[0.44,2.12]$} & & 1.28 & {$[0.74,2.21]$} & & 0.9 & {$[0.57,1.44]$} & \\
\hline Overweight & 0.35 & {$[0.11,1.14]$} & & 0.75 & {$[0.41,1.39]$} & & 0.79 & {$[0.45,1.38]$} & \\
\hline Obese & 0.54 & {$[0.22,1.35]$} & & 0.66 & {$[0.36,1.19]$} & & 0.78 & {$[0.51,1.22]$} & \\
\hline \multicolumn{10}{|c|}{ Lost to followup or missing disability status in 2006} \\
\hline Age & 1.00 & {$[0.94,1.06]$} & & 1.00 & {$[0.96,1.04]$} & & 1.01 & {$[0.97,1.04]$} & \\
\hline Female & 0.50 & {$[0.18,1.39]$} & & 1.40 & {$[0.48,4.08]$} & & 0.93 & {$[0.54,1.60]$} & \\
\hline \multicolumn{10}{|l|}{ Smoking status } \\
\hline Former smoker & 0.40 & {$[0.13,1.21]$} & & 0.69 & {$[0.23,2.04]$} & & 1.09 & {$[0.60,1.99]$} & \\
\hline Current smoker & 0.62 & {$[0.08,4.53]$} & & 0.86 & {$[0.30,2.48]$} & & 0.66 & {$[0.36,1.19]$} & \\
\hline Number of chronic conditions & 0.73 & {$[0.53,1.01]$} & & 0.88 & {$[0.66,1.16]$} & & 0.88 & {$[0.76,1.03]$} & \\
\hline Schooling & 1.16 & {$[0.97,1.40]$} & & 1.07 & {$[0.92,1.24]$} & & 1.03 & {$[0.93,1.15]$} & \\
\hline Live alone & 1.73 & {$[0.53,5.57]$} & & 1.43 & {$[0.68,3.01]$} & & 2.38 & {$[1.34,4.24]$} & $* *$ \\
\hline \multicolumn{10}{|l|}{ BMI categories } \\
\hline Underweight & 1.67 & {$[0.47,5.89]$} & & 1.42 & {$[0.72,2.82]$} & & 1.85 & {$[1.09,3.14]$} & * \\
\hline Overweight & 0.43 & {$[0.12,1.54]$} & & 0.90 & {$[0.36,2.27]$} & & 1.27 & {$[0.63,2.53]$} & \\
\hline Obese & 0.92 & {$[0.32,2.63]$} & & 1.14 & {$[0.49,2.65]$} & & 1.24 & {$[0.75,2.04]$} & \\
\hline$N$ & & 368 & & & 581 & & & 1,134 & \\
\hline $\mathrm{BIC}^{\prime}$ & & 30.33 & & & 62.47 & & & -42.91 & \\
\hline
\end{tabular}

ADL: activities of daily living; IADL: instrumental activities of daily living; RRR: relative risk ratio; CI: confidence interval; BMI: body mass index.

${ }^{a}$ Remaining with disability is the reference category. Normal weight is the reference category for BMI, living accompanied is the baseline category for household arrangement, and never smoked is the reference category for smoking status.

${ }^{* * *} P<0.001 ;{ }^{* *} P<0.05 ;{ }^{*} P<0.10$. 
TABLE 4: Relative risk ratios of the impact of body mass index categories and body mass index changes on disability transitions, São Paulo, Brazil-2000-2006.

\begin{tabular}{|c|c|c|c|c|c|c|c|c|c|}
\hline \multirow{2}{*}{ Variables } & \multicolumn{2}{|r|}{ ADL } & \multirow{2}{*}{$P$} & \multicolumn{2}{|r|}{ IADL } & \multirow{2}{*}{$P$} & \multicolumn{2}{|r|}{ NAGI } & \multirow{2}{*}{$P$} \\
\hline & $\mathrm{RRR}^{\mathrm{a}}$ & $95 \% \mathrm{CI}$ & & RRR & $95 \% \mathrm{CI}$ & & RRR & 95\% CI & \\
\hline \multicolumn{10}{|c|}{ Incidence of disability (reference $=$ remain free of disability) } \\
\hline Age & 1.10 & {$[1.07,1.13]$} & $* * *$ & 1.11 & {$[1.08,1.15]$} & $* * *$ & 1.05 & {$[1.01,1.09]$} & $*$ \\
\hline Female & 1.75 & {$[1.04,2.94]$} & * & 1.53 & {$[0.88,2.65]$} & & 2.44 & {$[1.44,4.12]$} & $* *$ \\
\hline \multicolumn{10}{|l|}{ Smoking status } \\
\hline Former smoker & 0.85 & {$[0.53,1.38]$} & & 1.14 & {$[0.67,1.95]$} & & 1.47 & {$[0.87,2.50]$} & \\
\hline Current smoker & 1.38 & {$[0.71,2.70]$} & & 1.45 & {$[0.67,3.16]$} & & 0.97 & {$[0.56,1.69]$} & \\
\hline Number of chronic conditions & 1.56 & {$[1.32,1.86]$} & $* * *$ & 1.33 & {$[1.12,1.59]$} & $* *$ & 1.25 & {$[0.92,1.68]$} & \\
\hline Schooling & 0.97 & {$[0.88,1.07]$} & & 0.92 & {$[0.82,1.03]$} & & 0.90 & {$[0.80,1.01]$} & \\
\hline Live alone & 0.85 & {$[0.50,1.44]$} & & 0.60 & {$[0.34,1.08]$} & & 1.01 & {$[0.42,2.41]$} & \\
\hline \multicolumn{10}{|l|}{ BMI categories } \\
\hline Underweight & 0.92 & {$[0.48,1.77]$} & & 1.73 & {$[1.05,2.84]$} & * & 0.93 & {$[0.49,1.79]$} & \\
\hline Overweight & 0.72 & {$[0.36,1.44]$} & & 1.39 & {$[0.67,2.88]$} & & 1.87 & {$[0.87,3.99]$} & \\
\hline Obese & 1.99 & {$[1.10,3.57]$} & * & 2.38 & {$[1.61,3.52]$} & $* * *$ & 1.22 & {$[0.66,2.27]$} & \\
\hline \multicolumn{10}{|l|}{ BMI change } \\
\hline Loss & 1.23 & {$[0.76,2.00]$} & & 0.99 & {$[0.62,1.60]$} & & 0.85 & {$[0.49,1.48]$} & \\
\hline Gain & 2.30 & {$[1.03,5.12]$} & * & 1.97 & {$[0.97,4.01]$} & & 2.15 & {$[1.20,3.85]$} & * \\
\hline$N$ & & 800 & & & 737 & & & 389 & \\
\hline $\mathrm{BIC}^{\prime}$ & & 27.46 & & & 9.40 & & & 28.56 & \\
\hline \multicolumn{10}{|c|}{ Recovery from disability (reference $=$ remain with disability) } \\
\hline Age & 0.92 & {$[0.87,0.98]$} & * & 0.93 & {$[0.88,0.99]$} & * & 0.95 & {$[0.91,0.99]$} & * \\
\hline Female & 0.43 & {$[0.13,1.47]$} & & 0.41 & {$[0.11,1.58]$} & & 0.53 & {$[0.28,1.01]$} & \\
\hline \multicolumn{10}{|l|}{ Smoking status } \\
\hline Former smoker & 0.34 & {$[0.09,1.30]$} & & 1.40 & {$[0.60,3.29]$} & & 1.46 & {$[0.74,2.87]$} & \\
\hline Current smoker & 1.11 & {$[0.29,4.17]$} & & 0.69 & {$[0.10,4.70]$} & & 0.97 & {$[0.38,2.44]$} & \\
\hline Number of chronic conditions & 0.64 & {$[0.45,0.90]$} & * & 0.94 & {$[0.68,1.29]$} & & 0.60 & {$[0.46,0.80]$} & $* * *$ \\
\hline Schooling & 1.05 & {$[0.87,1.28]$} & & 1.05 & {$[0.82,1.34]$} & & 1.03 & {$[0.87,1.22]$} & \\
\hline Live alone & 0.50 & {$[0.12,2.02]$} & & 1.03 & {$[0.22,4.85]$} & & 3.27 & {$[1.63,6.57]$} & $* *$ \\
\hline \multicolumn{10}{|l|}{ BMI categories } \\
\hline Underweight & 0.49 & {$[0.12,2.04]$} & & 0.16 & {$[0.02,1.40]$} & & 0.71 & {$[0.26,1.88]$} & \\
\hline Overweight & 0.89 & {$[0.27,2.88]$} & & 0.76 & {$[0.18,3.20]$} & & 0.86 & {$[0.31,2.36]$} & \\
\hline Obese & 0.42 & {$[0.17,1.05]$} & & 0.68 & {$[0.22,2.07]$} & & 0.43 & {$[0.21,0.86]$} & $*$ \\
\hline \multicolumn{10}{|l|}{ BMI change } \\
\hline Loss & 0.52 & {$[0.23,1.19]$} & & 0.53 & {$[0.21,1.35]$} & & 1.07 & {$[0.61,1.89]$} & \\
\hline Gain & 0.18 & {$[0.05,0.68]$} & $*$ & 0.64 & {$[0.15,2.73]$} & & 0.53 & {$[0.21,1.37]$} & \\
\hline$N$ & & 161 & & & 224 & & & 572 & \\
\hline $\mathrm{BIC}^{\prime}$ & & 31.87 & & & 91.45 & & & 85.22 & \\
\hline
\end{tabular}

ADL: activities of daily living; IADL: instrumental activities of daily living; RRR: relative risk ratio; CI: confidence interval; BMI: body mass index.

${ }^{a}$ Relative risk ratios were adjusted by smoking status. Remaining free of disability is the reference category for those who started without disability, and remaining with disability is the reference category for those who had disability in the baseline. Normal weight is the reference category for BMI. Stable weight is the baseline category for weight change. Results for lost in the followup were omitted (available upon request).

${ }^{* * *} P<0.001 ;{ }^{* *} P<0.05 ;{ }^{*} P<0.10$

mobility limitations [55]. A large proportion of older adults, however, do not engage in physical activity. In a study based on an urban sample in Brazil, for example, $71 \%$ of older adults reported living sedentary lives [56]. When asked about neighborhood characteristics related to concerns of leaving home to go out, most $(78 \%)$ reported fear of being robbed, while almost half $(48.2 \%)$ said that they were afraid of falling because of sidewalk defects [56]. Fear of falling due to poor sidewalk conditions was associated with a $62 \%$ increase in the expected number of ADL conditions [56]. Therefore, investments aimed at improving urban infrastructure and safety may be effective in addressing the health conditions of older adults in Brazil.

This study advances the literature on the impact of body weight and body weight changes on disability and mortality. This study, however, has some limitations. First, the 
data used in the study on disability measures were self-reported. Although this could be a possible source of bias, methodological studies have shown that self-reported data on functional disability are consistent with medical diagnoses [57]. Second, the use of BMI as a measure for body weight composition among older adults is very controversial as it does not take into account body fat distribution [17]. In addition, BMI at baseline can be associated with health status [16, 17]. Therefore, it is important to control for weight changes, which we accomplished in this study. Some authors have argued that waist circumference or waist-to-hip ratio could be better predictors of disability and mortality [10]; however, most studies to date have focused on the use of BMI and the categories used here. Other scholars have indicated that, at least for developed countries, information on BMI, waist circumference, or waist-to-hip ratio do not necessarily improve prediction of mortality due to cardiovascular disease; instead, they suggest using information on systolic blood pressure, diabetes status, and lipids when those are available [58]. And still others argue that-in addition to BMI-waist circumference and waist-to-hip ratio can be useful in better understanding mortality risks $[59,60]$. In Brazil, as in other developing countries, data on blood pressure and lipids are often lacking, so the use of anthropometric measures, such as waist circumference, may improve our understanding of the impact of body composition changes on mortality and disability. Third, the first wave of SABE focuses on the civilian population not residing in institutions. As a result, estimates may be biased if one expects institutionalized individuals, particularly those residing in nursing homes, to be more likely to have a higher prevalence of disability than the noninstitutionalized population. However, because the institutionalized population in Brazil is relatively small [61], this possible bias is likely not to be very significant.

\section{Conclusion}

This study confirms previous studies that have found obesity to be associated with increased disability in Brazilian older adults. Historically, Brazil has mainly been concerned with curbing malnutrition; however, in recent years, new policies have targeted the marketing of highly processed and unhealthy foods [5]. Owing to the fact that obesity rates in Brazil have been increasing drastically for the past three decades [6], our findings have important implications for policy makers in Brazil with regard to curbing disability risk by promoting the use of effective preventive measures to reduce body weight, thereby making healthy aging a reality.

\section{Author's Contribution}

F. C. D. Andrade planned the study, supervised the data analysis, and wrote the paper. A. I. N. M. Nazan contributed to the paper writing. M. L. Lebrão and Y. A. de O. Duarte collected the data, helped plan the study, including instrumentation, and revised the paper.

\section{Acknowledgments}

This study was supported by grants from FAPESP/Brazil, the Brazilian Ministry of Health, and the Lemann Institute for Brazilian Studies at the University of Illinois at UrbanaChampaign. The authors gratefully acknowledge the feedback received at the 2012 Population Association of America Annual Meeting. They also thank Fernão Dias de Lima for the careful management of the database.

\section{References}

[1] D. Cotlear, Population Aging? Is Latin America Ready? World Bank, Washington, DC, USA, 2011.

[2] K. Kinsella and W. He, An Aging World: 2008, Government Printing Office, Washington, DC, USA, 2009.

[3] Population Division of the Department of Economic and Social Affairs of the United Nations Secretariat, World Population Prospects: The 2010 Revision, United Nations, New York, NY, USA, 2011.

[4] S. Al Snih, J. E. Graham, Y. F. Kuo, J. S. Goodwin, K. S. Markides, and K. J. Ottenbacher, "Obesity and disability: relation among older adults living in latin america and the caribbean," American Journal of Epidemiology, vol. 171, no. 12, pp. 1282-1288, 2010.

[5] B. M. Popkin, L. S. Adair, and S. W. Ng, "Global nutrition transition and the pandemic of obesity in developing countries," Nutrition Reviews, vol. 70, no. 1, pp. 3-21, 2012.

[6] C. A. Monteiro, W. L. Conde, and B. M. Popkin, "Income-specific trends in obesity in Brazil: 1975-2003," American Journal of Public Health, vol. 97, no. 10, pp. 1808-1812, 2007.

[7] C. A. Monteiro, W. L. Conde, and B. M. Popkin, "The burden of disease from undernutrition and overnutrition in countries undergoing rapid nutrition transition: a view from Brazil," American Journal of Public Health, vol. 94, no. 3, pp. 433-434, 2004.

[8] C. A. Monteiro, W. L. Conde, and B. M. Popkin, "Independent effects of income and education on the risk of obesity in the Brazilian adult population," Journal of Nutrition, vol. 131, no. 3, pp. 881S-886S, 2001.

[9] L. P. Corona, T. R. Pereira de Brito, D. P. Nunes et al., "Nutritional status and risk for disability in instrumental activities of daily living in older Brazilians," Public Health Nutrition, vol. 13, pp. 1-6, 2012.

[10] M. Monteverde, K. Noronha, A. Palloni, and B. Novak, "Obesity and excess mortality among the elderly in the United States and Mexico," Demography, vol. 47, no. 1, pp. 79-96, 2010.

[11] S. Al Snih, K. J. Ottenbacher, K. S. Markides, Y. F. Kuo, K. Eschbach, and J. S. Goodwin, "The effect of obesity on disability versus mortality in older Americans," Archives of Internal Medicine, vol. 167, no. 8, pp. 774-780, 2007.

[12] I. M. Majer, W. J. Nusselder, J. P. MacKenbach, and A. E. Kunst, "Life expectancy and life expectancy with disability of normal weight, overweight, and obese smokers and nonsmokers in Europe," Obesity, vol. 19, no. 7, pp. 1451-1459, 2011.

[13] H. K. Vincent, K. R. Vincent, and K. M. Lamb, "Obesity and mobility disability in the older adult," Obesity Reviews, vol. 11, no. 8, pp. 568-579, 2010.

[14] I. A. Lang, D. J. Llewellyn, K. Alexander, and D. Melzer, "Obesity, physical function, and mortality in older adults," Journal of the American Geriatrics Society, vol. 56, no. 8, pp. 14741478, 2008. 
[15] S. Larrieu, K. Pérès, L. Letenneur et al., "Relationship between body mass index and different domains of disability in older persons: the 3C study," International Journal of Obesity, vol. 28, no. 12, pp. 1555-1560, 2004.

[16] D. E. Alley and V. W. Chang, "The changing relationship of obesity and disability, 1988-2004," Journal of the American Medical Association, vol. 298, no. 17, pp. 2020-2027, 2007.

[17] D. E. Alley, L. Ferrucci, M. Barbagallo, S. A. Studenski, and T. B. Harris, "A research agenda: the changing relationship between body weight and health in aging," Journals of Gerontology Series A, vol. 63, no. 11, pp. 1257-1259, 2008.

[18] A. P. Carson, D. N. Holmes, and D. L. Howard, "Weight change and functional limitations among older adults in North Carolina," Journal of Community Health, vol. 35, no. 6, pp. 586-591, 2010.

[19] S. Al Snih, M. A. Raji, K. S. Markides, K. J. Ottenbacher, and J. S. Goodwin, "Weight change and lower body disability in older Mexican Americans," Journal of the American Geriatrics Society, vol. 53, no. 10, pp. 1730-1737, 2005.

[20] A. B. De Gonzalez, P. Hartge, J. R. Cerhan et al., "Body-mass index and mortality among 1.46 million white adults," New England Journal of Medicine, vol. 363, no. 23, pp. 2211-2219, 2010.

[21] L. C. Hwang, S. C. Chen, J. J. Tjung, H. Y. Chiou, C. J. Chen, and C. H. Tsai, "Body mass index as a predictor of mortality in older people in Taiwan," International Journal of Gerontology, vol. 3, no. 1, pp. 39-46, 2009.

[22] Prospective Studies Collaboration, "Body-mass index and cause-specific mortality in 900000 adults: collaborative analyses of 57 prospective studies," The Lancet, vol. 373, no. 9669, pp. 1083-1096, 2009.

[23] A. Peeters, J. J. Barendregt, F. Willekens et al., "Obesity in adulthood and its consequences for life expectancy: a life-table analysis," Annals of Internal Medicine, vol. 138, no. 1, pp. 24-32, 2003.

[24] A. C. Tsai and M. Hsiao, "The association of body mass index (BMI) with all-cause mortality in older Taiwanese: results of a national cohort study," Archives of Gerontology and Geriatrics, vol. 55, no. 2, pp. 217-220, 2012.

[25] I. Janssen and A. E. Mark, "Elevated body mass index and mortality risk in the elderly," Obesity Reviews, vol. 8, no. 1, pp. 41-59, 2007.

[26] R. Bender, K. H. Jöckel, C. Trautner, M. Spraul, and M. Berger, "Effect of age on excess mortality in obesity," Journal of the American Medical Association, vol. 281, no. 16, pp. 1498-1504, 1999.

[27] K. M. Flegal, B. I. Graubard, D. F. Williamson, and M. H. Gail, "Excess deaths associated with underweight, overweight, and obesity," Journal of the American Medical Association, vol. 293, no. 15, pp. 1861-1867, 2005.

[28] R. Huxley, F. Barzi, and M. Woodward, "Excess risk of fatal coronary heart disease associated with diabetes in men and women: meta-analysis of 37 prospective cohort studies," British Medical Journal, vol. 332, no. 7533, pp. 73-76, 2006.

[29] M. Reuser, L. Bonneux, and F. Willekens, "The burden of mortality of obesity at middle and old age is small. A life table analysis of the US Health and Retirement Survey," European Journal of Epidemiology, vol. 23, no. 9, pp. 601-607, 2008.

[30] S. L. Reynolds, Y. Saito, and E. M. Crimmins, "The impact of obesity on active life expectancy in older American men and women," Gerontologist, vol. 45, no. 4, pp. 438-444, 2005.

[31] E. Wong, B. Wang, L. Garrison et al., "Examining the BMImortality relationship using fractional polynomials," BMC Medical Research Methodology, vol. 11, no. 1, article 175, 2011.
[32] A. Zajacova and S. A. Burgard, "Shape of the BMI-mortality association by cause of death, using generalized additive models: NHIS 1986-2006," Journal of Aging and Health, vol. 24, no. 2, pp. 191-211, 2012.

[33] J. T. Gronniger, "A semiparametric analysis of the relationship of body mass index to mortality," American Journal of Public Health, vol. 96, no. 1, pp. 173-178, 2006.

[34] A. Palloni, G. Pinto-Aguirre, and M. Pelaez, "Demographic and health conditions of ageing in Latin America and the Caribbean," International Journal of Epidemiology, vol. 31, no. 4, pp. 762-771, 2002.

[35] R. Wong, M. Peláez, A. Palloni, and K. Markides, "Survey data for the study of aging in Latin America and the Caribbean: selected studies," Journal of Aging and Health, vol. 18, no. 2, pp. 157-179, 2006.

[36] C. Albala, M. L. Lebrão, E. M. L. Diaz et al., "Salud, Bienestar y Envejecimiento (SABE): metodologia de la encuesta t perfil de la población estudiada," Pan American Journal of Public Health, vol. 17, no. 5-6, pp. 307-322, 2005.

[37] F. C. D. Andrade, P. E. Guevara, M. L. Lebrão, Y. A. de Oliveira Duarte, and J. L. F. Santos, "Gender differences in life expectancy and disability-free life expectancy among older adults in São Paulo, Brazil," Women's Health Issues, vol. 21, no. 1, pp. 6470, 2011.

[38] M. L. Lebrão and R. Laurenti, "Saúde, bem-estar e envelhecimento: o estudo SABE no município de São Paulo," Revista Brasileira De Epidemiologia, vol. 8, no. 2, pp. 127-141, 2005.

[39] F. C. D. Andrade, I. Vazquez-Vidal, and T. Flood, "One-year follow-up changes in weight are associated with changes in blood pressure in young Mexican adults," Public Health, vol. 126, no. 6, pp. 535-540, 2012.

[40] S. Walter, A. Kunst, J. MacKenbach, A. Hofman, and H. Tiemeier, "Mortality and disability: the effect of overweight and obesity," International Journal of Obesity, vol. 33, no. 12, pp. 14101418, 2009.

[41] H. Dong, M. Unosson, E. Wressle, and J. Marcusson, "Health consequences associated with being overweight or obese: a Swedish population-based study of 85-year-olds," Journal of the American Geriatrics Society, vol. 60, no. 2, pp. 243-250, 2012.

[42] C. S. Ritchie, J. L. Locher, D. L. Roth, T. McVie, P. Sawyer, and R. Allman, "Unintentional weight loss predicts decline in activities of daily living function and life-space mobility over 4 years among community-dwelling older adults," Journals of Gerontology Series A, vol. 63, no. 1, pp. 67-75, 2008.

[43] D. T. Villareal, C. M. Apovian, R. F. Kushner, and S. Klein, "Obesity in older adults: technical review and position statement of the American Society for Nutrition and NAASO, The Obesity Society," American Journal of Clinical Nutrition, vol. 82, no. 5, pp. 923-934, 2005.

[44] M. Thinggaard, R. Jacobsen, B. Jeune, T. Martinussen, and K. Christensen, "Is the relationship between bmi and mortality increasingly u-shaped with advancing age? A 10-year follow-up of persons aged 70-95 years," Journals of Gerontology Series A, vol. 65 , no. 5, pp. 526-531, 2010.

[45] J. P. Curtis, J. G. Selter, Y. Wang et al., "The obesity paradox: body mass index and outcomes in patients with heart failure," Archives of Internal Medicine, vol. 165, no. 1, pp. 55-61, 2008.

[46] B. E. Alvarado, M. V. Zunzunegui, F. Béland, M. Sicotte, and L. Tellechea, "Social and gender inequalities in depressive symptoms among urban older adults of Latin America and the Caribbean," Journals of Gerontology Series B, vol. 62, no. 4, pp. S226-S237, 2007. 
[47] F. C. Andrade, "Measuring the impact of diabetes on life expectancy and disability-free life expectancy among older adults in Mexico," The Journals of Gerontology Series B, vol. 65, no. 3, pp. 381-389, 2010.

[48] M. C. S. Camargos, C. J. Machado, and R. Do Nascimento Rodrigues, "Disability life expectancy for the elderly, city of São Paulo, Brazil, 2000: gender and educational differences," Journal of Biosocial Science, vol. 39, no. 3, pp. 455-463, 2007.

[49] M. C. S. Camargos, C. J. Machado, and R. N. Rodrigues, "Life expectancy among elderly Brazilians in 2003 according to different levels of functional disability," Cadernos de Saude Publica, vol. 24, no. 4, pp. 845-852, 2008.

[50] S. Reyes-Beaman, C. Jagger, C. Garcia-Peña, O. Muñoz, P. E. Beaman, and B. Stafford, "Active life expectancy of older people in Mexico," Disability and Rehabilitation, vol. 27, no. 5, pp. 213219, 2005.

[51] C. A. Reyes-Ortiz, G. V. Ostir, M. Pelaez, and K. J. Ottenbacher, "Cross-national comparison of disability in Latin American and Caribbean persons aged 75 and older," Archives of Gerontology and Geriatrics, vol. 42, no. 1, pp. 21-33, 2006.

[52] R. O. Guerra, B. E. Alvarado, and M. V. Zunzunegui, "Life course, gender and ethnic inequalities in functional disability in a Brazilian urban elderly population," Aging, vol. 20, no. 1, pp. 53-61, 2008.

[53] J. L. F. Santos, M. L. Lebrão, Y. A. O. Duarte, and F. D. De Lima, "Functional performance of the elderly in instrumental activities of daily living: an analysis in the municipality of São Paulo, Brazil," Cadernos de Saude Publica, vol. 24, no. 4, pp. 879-886, 2008.

[54] M. F. Lima-Costa, S. V. Peixoto, D. L. Matos, J. O. A. Firmo, and E. Uchôa, "Predictors of 10 -year mortality in a population of community-dwelling Brazilian elderly: the Bambuí cohort study of aging," Cadernos De Saúde Pública, vol. 27, pp. s360s369, 2011.

[55] N. M. de Vries, C. D. van Ravensberg, J. S. Hobbelen, M. G. Olde Rikkert, J. B. Staal, and M. W. Nijhuis-van der Sanden, "Effects of physical exercise therapy on mobility, physical functioning, physical activity and quality of life in community-dwelling older adults with impaired mobility, physical disability and/or multimorbidity: a meta-analysis," Ageing Research Reviews, vol. 11, no. 1, pp. 136-149, 2012.

[56] F. R. Ferreira, C. C. César, V. P. Camargos, M. F. Lima-Costa, and F. A. Proietti, "Aging and urbanization: the neighborhood perception and functional performance of elderly persons in belo horizonte metropolitan area-Brazil," Journal of Urban Health, vol. 87, no. 1, pp. 54-66, 2010.

[57] M. V. Zunzunegui, B. E. Alvarado, F. Béland, and B. Vissandjee, "Explaining health differences between men and women in later life: a cross-city comparison in Latin America and the Caribbean," Social Science and Medicine, vol. 68, no. 2, pp. 235-242, 2009.

[58] D. Wormser, S. Kaptoge, E. Di Angelantonio et al., "Separate and combined associations of body-mass index and abdominal adiposity with cardiovascular disease: collaborative analysis of 58 prospective studies," The Lancet, vol. 377, no. 9771, pp. 10851095, 2011.

[59] T. Pischon, H. Boeing, K. Hoffmann et al., "General and abdominal adiposity and risk of death in Europe," New England Journal of Medicine, vol. 359, no. 20, pp. 2105-2120, 2008.

[60] T. Pischon, "Commentary: use of the body mass index to assess the risk of health outcomes: time to say goodbye?" International Journal of Epidemiology, vol. 39, no. 2, pp. 528-529, 2010.
[61] A. A. Camarano and S. Kanso, "As instituições de longa permanência para idosos no Brasil," Revista Brasileira de Estudos de População, vol. 27, no. 1, pp. 232-235, 2010. 


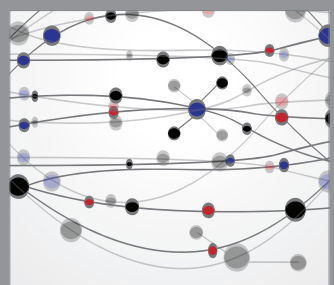

The Scientific World Journal
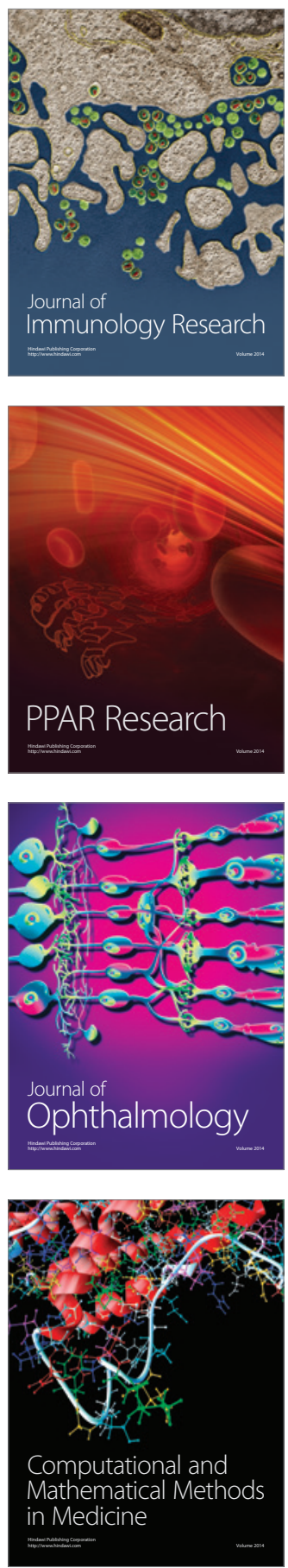

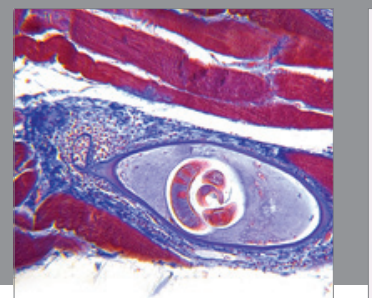

Gastroenterology

Research and Practice
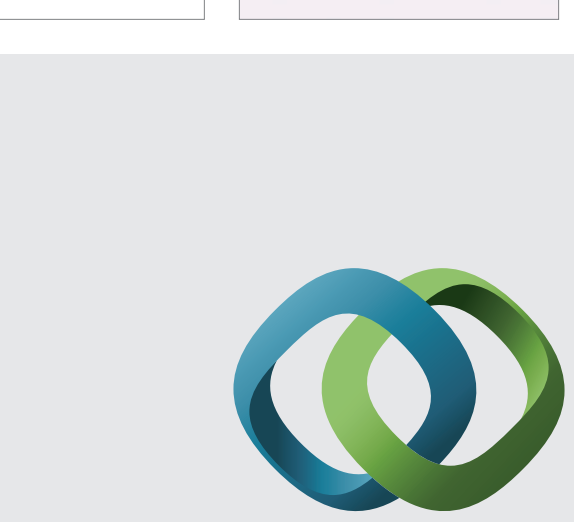

\section{Hindawi}

Submit your manuscripts at

http://www.hindawi.com
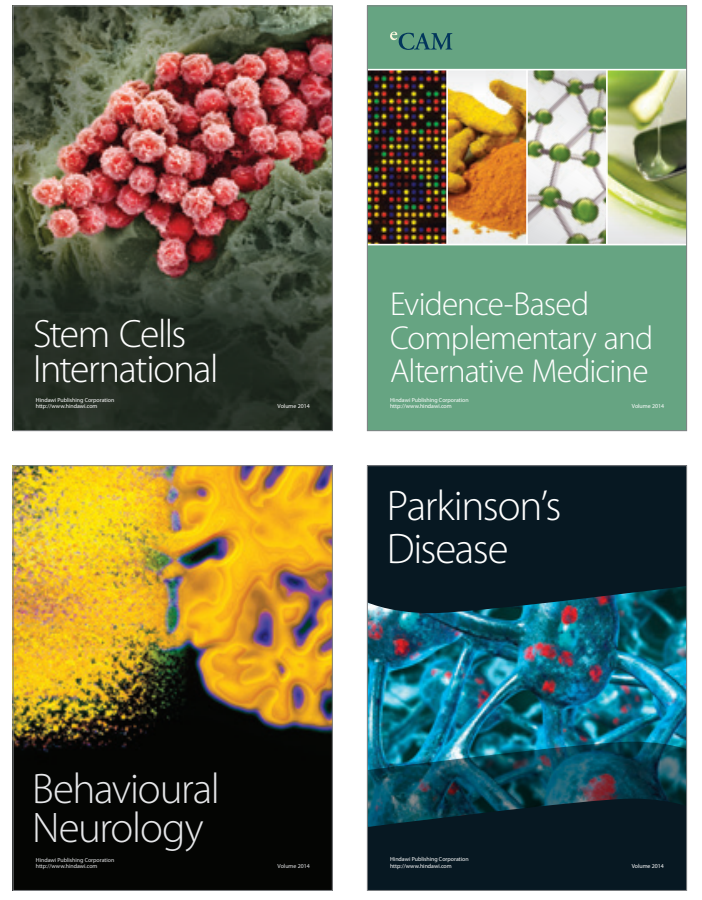
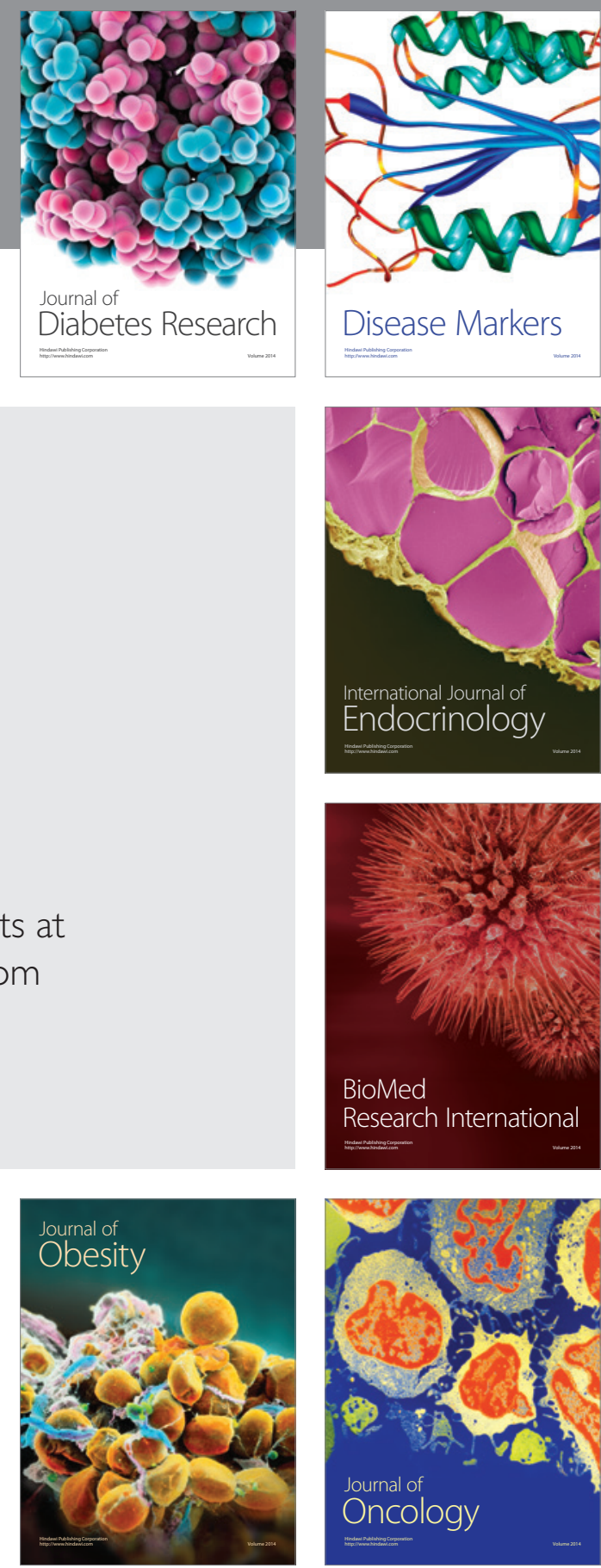

Disease Markers
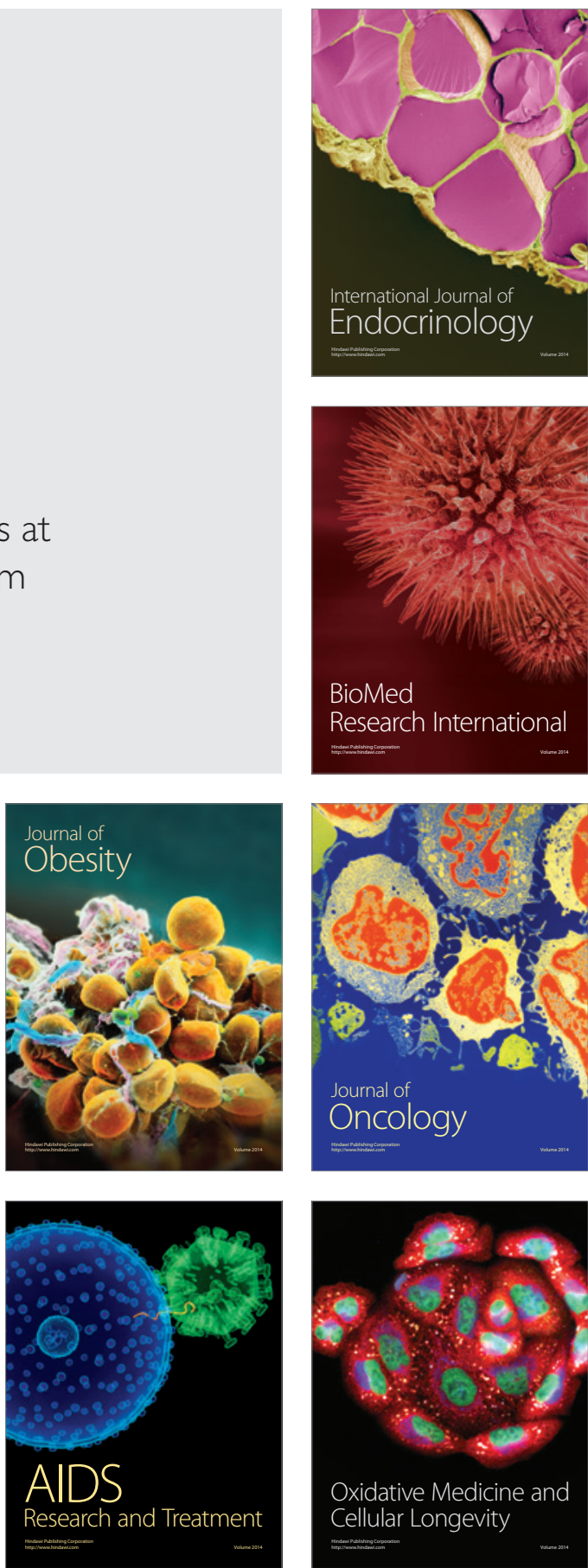